\title{
The Levels of Toxic Air Pollutants in Kitchens with Traditional Stoves in Rural Sierra Leone
}

\author{
Eldred Tunde Taylor ${ }^{1,2 *}$, Satoshi Nakai ${ }^{1}$ \\ ${ }^{1}$ Graduate School of Environment and Information Sciences, Yokohama National University, Yokohama, Japan; ${ }^{2}$ Institute of Envi- \\ ronmental Management and Quality Control, Njala University, Njala, Sierra Leone. \\ Email: *elduredo@gmail.com
}

Received July $30^{\text {th }}, 2012$; revised August 29 $9^{\text {th }}, 2012$; accepted September $30^{\text {th }}, 2012$

\begin{abstract}
Wood and charcoal fuels, widely used in Sierra Leone for cooking, may impact indoor air quality. Until now, there is presently lack of data to quantify the extent of impact. In this study, concentrations of polycyclic aromatic hydrocarbons (PAHs), suspended particulate matter (SPM) and carbon monoxide (CO) were measured in kitchens with wood and charcoal stoves during cooking in rural areas. $\mathrm{PAH}$ contents of $\mathrm{PM}_{2.5}$ and $\mathrm{PM}_{2.5-10}$ fractions were analyzed using HPLC/FLD and SPM and CO were monitored in realtime. Mean \pm SD concentrations of $\mathrm{PM}_{2.5}$ related $\sum_{11} \mathrm{PAHs}, \mathrm{PM}$ and $\mathrm{CO}$ were $2127 \pm 1173 \mathrm{ng} / \mathrm{m}^{3}, 1686 \pm 973 \mu \mathrm{g} / \mathrm{m}^{3}$ and $28 \pm 9 \mathrm{ppm}$ for wood stoves; and $158 \pm 106 \mathrm{ng} / \mathrm{m}^{3}, 315 \pm 205$ $\mu \mathrm{g} / \mathrm{m}^{3}$ and $42 \pm 21 \mathrm{ppm}$ for charcoal stoves, respectively. PAHs were largely associated with $\mathrm{PM}_{2.5}$ than $\mathrm{PM}_{2.5-10}$. Maximum 1-hr time averaged \pm SD CO concentration for kitchens with wood and charcoal stoves were $44 \pm 21 \mathrm{ppm}$ and $77 \pm 49 \mathrm{ppm}$, respectively. Generally, concentrations of PAHs, PM and CO were higher than the WHO recommended guidelines which raise concern with regards to health risks. Given the existing evidence of reduced emissions of PAHs, PM and CO from cleaner fuels, a transition from cooking with wood and charcoal to cleaner fuels would provide an improvement in indoor air quality, a requirement for good health.
\end{abstract}

Keywords: Indoor Air; Biomass-Fuel; Polycyclic Aromatic Hydrocarbons; Suspended Particulate Matter; Carbon Monoxide

\section{Introduction}

The release of air pollutants due to burning biomass fuels (wood, dung, crop residue, charcoal) is recognized to be an important issue for indoor air quality mainly in developing countries. These fuels are primarily used for cooking and space heating. Roughly half of the global population, around three billion, depend on biomass fuels for domestic energy [1]. These fuels are traditionally burnt in simple stoves with poor combustion efficiency, under poor ventilation conditions. This often results in emission of smoke that contains several health deteriorating substances at varying concentrations which can pose threat to humans. These substances in smoke are referred to as toxic air pollutants. About 1.5 million deaths around the world is attributed to exposure to smoke from biomass fuels, with more than two thirds of these deaths occurring in South East Asia and Sub-Sahara Africa [2]. Therefore, indoor air pollution caused by biomass smoke is a major public health concern. Among the indoor air toxic pollutants generated

"Corresponding author. from kitchen smoke are polycyclic aromatic hydrocarbons (PAHs); suspended particulate matter (SPM), a form of particulate matter; and carbon monoxide (CO) [3].

PAHs are ubiquitous environmental pollutants with toxic and carcinogenic properties, and are included in the list of hazardous air pollutants by the US Environmental Protection Agency (USEPA). The International Agency for Research on Cancer has classified PAHs, particularly Benzo(a)pyrene (BaP) as Group 1 human carcinogen [4]. Several countries and organizations have set up protective health standards for $\mathrm{BaP}$ based on the carcinogenic potential of inhaled particulate PAHs in ambient air. For instance, the guideline value of $\mathrm{BaP}$ proposed by the $4^{\text {th }}$ Daughter Directive $(2004 / 107 / \mathrm{EC})$ is $1 \mathrm{ng} / \mathrm{m}^{3} ; 0.25 \mathrm{ng} /$ $\mathrm{m}^{3}$ in USA [5]; $0.25 \mathrm{ng} / \mathrm{m}^{3}$ in UK [5]; $10 \mathrm{ng} / \mathrm{m}^{3}$ in China [6]. The likely health outcome of exposure to PAHs is cancer. For instance, exposure to smoky fuels has been associated with increased lung cancer in China [7]. Another common pollutant in smoke is particulate matter (PM), and it is one of the widely studied indicator species of indoor air pollution that arises from biomass smoke. There is much research focus now on $\mathrm{PM}_{2.5}$ released 
from biomass smoke. This size fraction can penetrate deep into human lungs making it a major health risk $[8,9]$. Previous studies have linked particulate matter derived from biomass smoke to acute respiratory infections (ARI) and chronic obstructive pulmonary disease (COPD) [1013]. As the combustion process of biomass fuels is often incomplete, it generates $\mathrm{CO}$, linked to cardiovascular diseases [14].

In Africa, more than $70 \%$ of the population largely depends on biomass fuels for domestic energy [15]. Wood and charcoal fuels are largely burnt in poorly ventilated kitchens for domestic cooking. Several studies have reported various levels of indoor air pollutants derived from these fuels in some African countries [16-22]. The consumption of biomass energy in Sierra Leone has been described in details elsewhere [23]. Sierra Leone was ranked among one of the 21 worst affected countries where close to $5 \%$ of deaths and disease is caused by indoor air pollution, partly as a consequence of the dependence on biomass fuels [1]. As these fuels are used in kitchens that are poorly ventilated, they are a cause for indoor air quality concerns. The emission levels of pollutants such as PAHs, $\mathrm{PM}_{10}$ and $\mathrm{CO}$ are notably high during cooking periods $[16,18,24,25]$. For instance, total PAHs concentration during cooking and non cooking periods were $6.21 \mu \mathrm{g} / \mathrm{m}^{3}$ and $1.41 \mu \mathrm{g} / \mathrm{m}^{3}$ respectively [24], and a similar observation made for $\mathrm{PM}_{10}$ [25]. The issue of smoky kitchens in Sierra Leone is common because of the local reliance on wood and charcoal stoves for cooking. The extent of emissions that characterize these kitchens, however, has not been studied; hence, there is lack of data on indoor air pollution in Sierra Leone. In this report, we focused on the levels of PAHs, $\mathrm{PM}$ and $\mathrm{CO}$ in rural kitchens, considering the environmental health implications of these pollutants. Hence, the levels of particulate PAHs, PM and CO generated during cooking in kitchens with wood and charcoal stoves were measured in rural Sierra Leone, and their implication to public health highlighted.

\section{Materials and Methods}

\subsection{Study Area, Kitchen Description and Sampling}

The study took place in Waterloo and Tombo in the Western Rural District of Sierra Leone Figure 1. As typical rural communities, biomass fuels (wood and charcoal) consumption is high in Waterloo and Tombo. Through our field observations, we estimated Waterloo and Tombo to have more than $75 \%$ and $85 \%$ of homes that use charcoal and wood, respectively.

Waterloo is a rural community that has expanded in size in recent years due to congestion in the commercial capital Freetown. It is located $30 \mathrm{~km}$ east of Freetown.

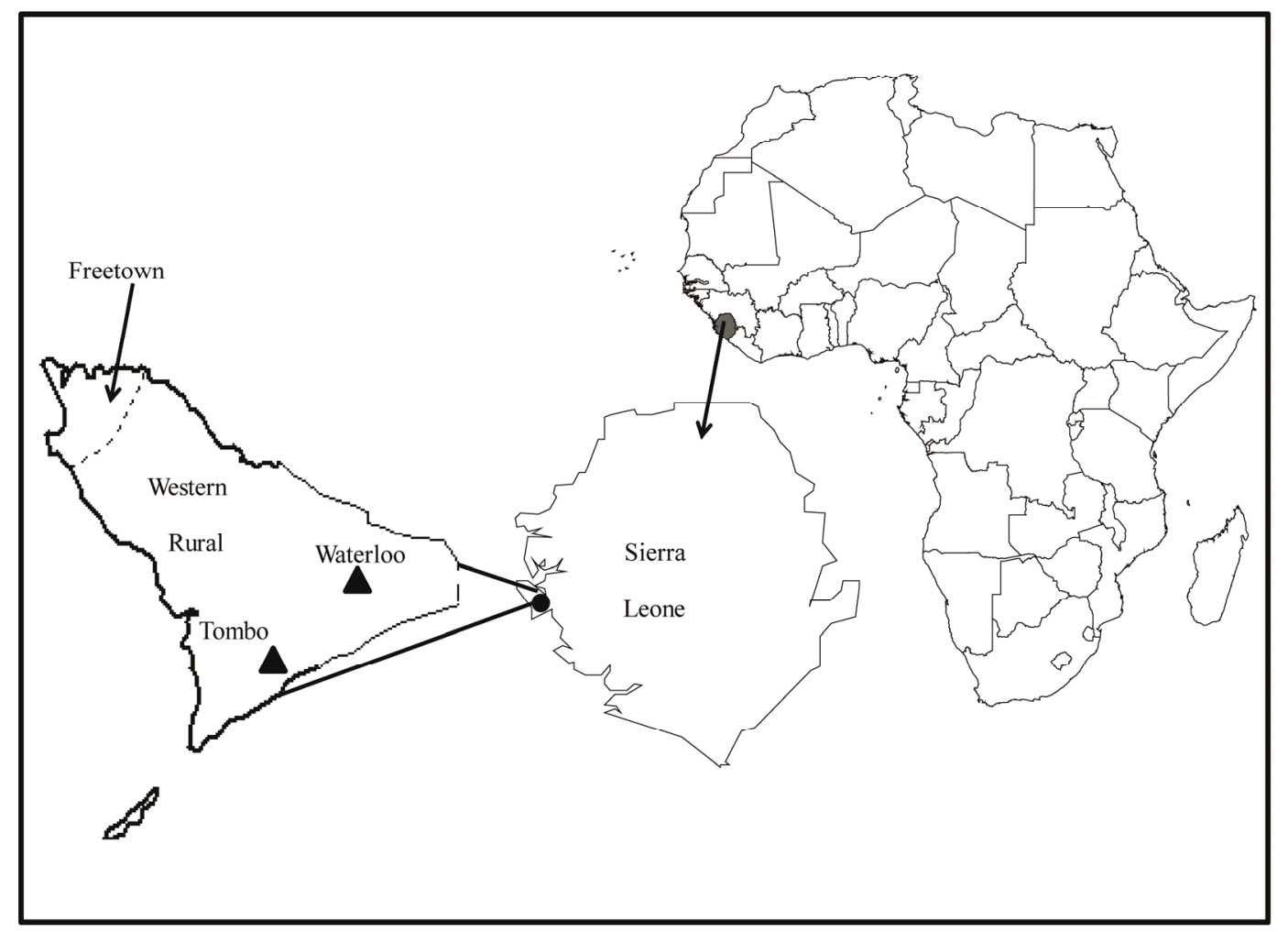

Figure 1. Map of Africa indicating Sierra Leone; with an extended map of Western Sierra Leone showing Western Rural Area with sampling zones in black triangles, and Freetown the capital city in Western Urban Area. 
Several homes are constructed from cement bricks and with corrugated metal sheets roofing. Monitored homes comprised $3-4$ bedrooms with indoor kitchens. The kitchens have paved cement floor, a window and a door that were opened during cooking (opened kitchen). Charcoal stove (known locally as wonder stove) was used in the monitored homes. The wonder stove is cylindrically shaped and about 15 inches tall. The inside is made of clay but has a metallic outer body. It has indented surface and solid base in the middle that retain cooking fuel, three metal rings on top that hold cooking pots and a large base with vacuum that hold ashes. This information is found in Supplementary Figure 1 at the end of the manuscript texts.

Tombo community is characterized by settlements where kitchen is separated from the main home. Homes are predominantly made from mud with corrugated metal or thatched roofing. It is $14 \mathrm{~km}$ away from Waterloo along the Freetown Peninsula. Monitored homes consisted of 1 - 3 bedrooms with separate outdoor kitchens. Kitchens were close to a square in structure with walls made from mud or metal sheets, unpaved floor and a single door and window that were opened during cooking (opened kitchen). Wood stoves (consisting of three stones arranged into a tripod) were used in these kitchens (open wood fires); (Supplementary Figure 2). Wood is normally obtained from nearby forests and thickets from which charcoal is processed, transported and sold to communities where the demand is high.

Ten homes having kitchens with wood stoves and another ten with charcoal stoves were monitored in the two different communities for particulate PAHs and CO. Five homes from the above ten in each community were similarly monitored for PM. Oral informed consent was obtain

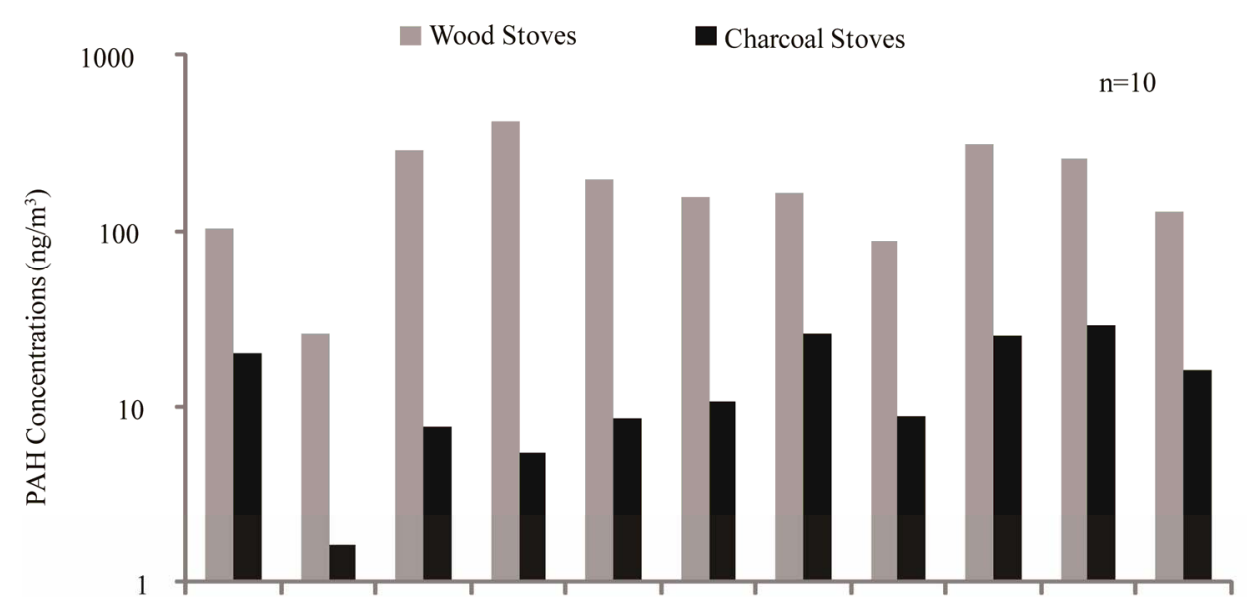

(a)

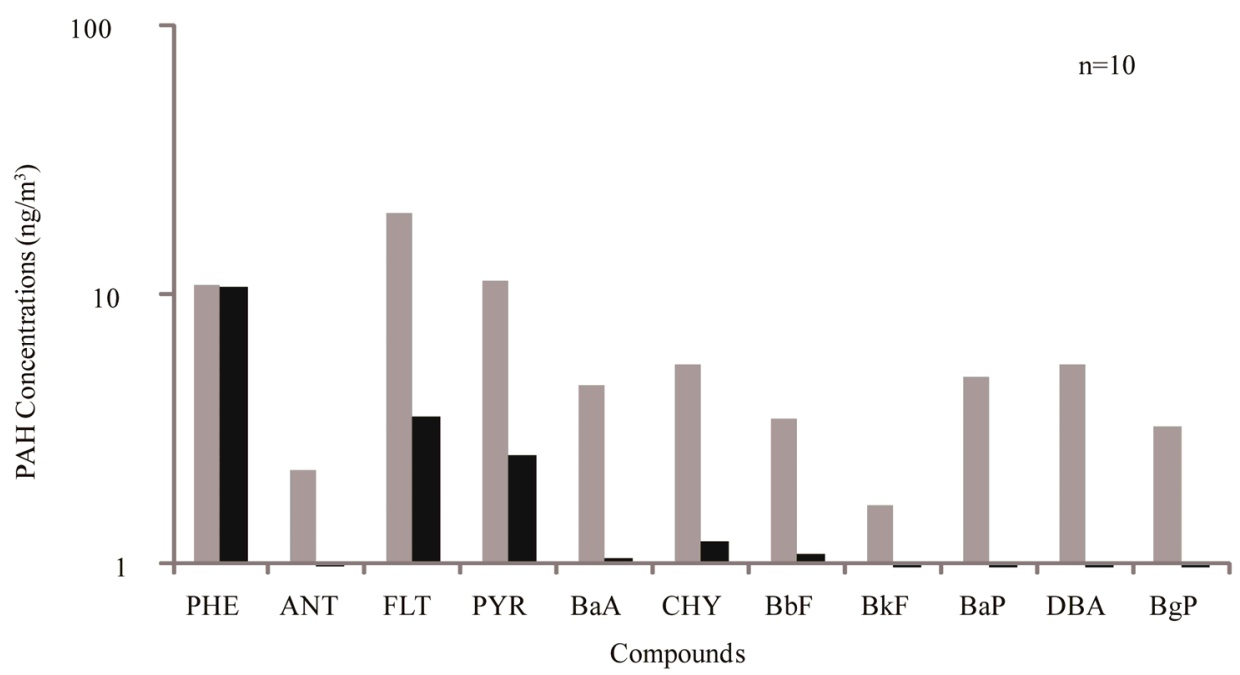

(b)

Figure 2. Distribution profile of individual (a) $\mathbf{P M}_{2.5}$ and (b) $\mathbf{P M}_{2.5-10}$ bound $\mathbf{P A H s}$ released in kitchens with wood and charcoal stoves. PHE—-phenanthrene; ANT—anthracene; FLT—fluoranthene; PYR—pyrene; BaA—benzo(a)anthracene; CHY— chrysene; BbF—benzo(b)fluoranthene; BkF—benzo(k)fluoranthene; BaP—benzo(a)pyrene; DBA—dibenzo(a,h)anthracene; BgP—benzo(g,h,i)pyrelene. 
ed through the head of each home we monitored a day before the actual monitoring commenced.

\subsection{Measurement of Indoor Air Toxics}

Toxic air pollutants-PAHs, PM and CO-were all measured in kitchens by placing respective samplers at a height of $1 \mathrm{~m}$ above the ground and $1 \mathrm{~m}$ off the stove, representing the breathing and active cooking zone of a sitting woman. Samples were cumulatively measured for two cooking activities each lasting for two hours (for PAHs), and real time monitoring made (for PM and $\mathrm{CO}$ ) in the kitchen for the same duration of measurement for PAHs.

\subsubsection{Polycyclic Aromatic Hydrocarbons}

Air particulate matter were collected on a $20 \mathrm{~mm}$ (for $\mathrm{PM}_{2.5}$ ) and $10 \mathrm{~mm}$ (for $\mathrm{PM}_{2.5-10}$ ) diameter Teflon coated glass fiber filter using Sibata ATPS-20H dual impactor (Sibata Scientific Technology Limited) [26]. No gravimetric measurement of particulate matter was made. A uniform flow rate of $1.5 \mathrm{l} / \mathrm{min}$ was maintained during cooking for each kitchen. Samples collected in each day were wrapped in aluminum foils and stored at freezing temperature. After the field work was complete, all the samples were transported to Japan for analysis.

\subsubsection{Suspended Particulate Matter}

The information regarding the measurement procedure for SPM has been described elsewhere [23]. As SPM is a form of PM, the term for the latter was used in this study, and we considered the measured values obtained for PM to be similar to $\mathrm{PM}_{10}$.

\subsubsection{Carbon Monoxide}

CO was monitored by Lascar EL-USB-CO data logger with USB interface. Concentration of CO was logged every minute.

\subsection{PAHs Extraction, Analysis and Quality Control}

The sample extraction process is a modified method that has been previously reported [27] and recently reported [26]. In brief, PAHs were extracted from the filters with a mixture of benzene/ethanol in the ratio (3:1) in an ultrasonic bath for 50 minutes in 2 cycles. After centrifugation at $3000 \mathrm{rpm}$ for 10 minutes, the extracts were filtered and the filtrates were transferred to a rotary evaporating flask into which $100 \mu \mathrm{l}$ of dimethyl sulfoxide was added for preservation. Final volume was adjusted to 1 $\mathrm{ml}$ by adding $900 \mu \mathrm{l}$ of acetonitrile and the sample solution was injected into the following HPLC system.

Chromatographic separation and identification of 11 PAHs was enhanced by HPLC system (HP1100; Agilent
Technologies) equipped with fluorescence detector supported by diode array detector. A guard column $(30 \times 4.6$ $\mathrm{mm}, 5 \mu \mathrm{m})$ for clean up and an analytical column of PAHs $(125 \times 4.6 \mathrm{~mm}, 5 \mu \mathrm{m})$ were $\mathrm{C}_{18}$ EnviroSep-PP (Phenomenex). Concentrations of $11 \mathrm{PAHs}$ were quantified according to their elution order as follows: Phenanthrene [PHE], anthracene [ANT], Fluoranthene [FLT], Pyrene [PYR], Benzo(a)anthracene [BaA], Chrysene [CHY] Benzo(b)fluoranthene [BbF], Benzo(k)fluoranthene [BkF], Benzo(a)pyrene [BaP], Dibenzo(a,h)anthracene [DBA] and Benzo(ghi)pyrelene [BgP].

Results presented were corrected for trace levels of PHE and PYR from the field blank filters. A five-point calibration curve of individual PAH at different concentrations was prepared to determine the linearity of responses, and a good correlation coefficient of over 0.97 was obtained for each PAH species. Deuterated PAHs (phenanthrene- $\mathrm{d}_{10}$, pyrene- $\mathrm{d}_{10}$ and benzo(a)pyrene- $\mathrm{d}_{12}$ ) were added as surrogate to examine extraction and clean up procedures, and the surrogates recoveries ranged from $85 \%$ to $96 \%$. The recoveries were acceptable and compared well with those reported in other studies for PAHs $[28,29]$.

\subsection{Data Analysis}

The total concentrations of eleven PAHs are represented as $\left(\sum_{11} \mathrm{PAHs}\right)$. Average concentrations of $\sum_{11} \mathrm{PAHs}$ were calculated separately for $\mathrm{PM}_{2.5}$ and $\mathrm{PM}_{2.5-10}$ bound PAHs released from wood and charcoal stoves. PM and CO concentrations for four hours were time averaged for each home with wood or charcoal stove. Using the time averaged concentrations, the arithmetic means were calculated. Maximum 1-hr arithmetic means were also calculated for each kitchen for $\mathrm{CO}$ to compare with $\mathrm{WHO}$ guideline. $\mathrm{BaP}$ equivalent concentrations of PAHs were estimated for wood and charcoal with the procedure described elsewhere [26]. Statistical analysis was conducted using JMP 8 (SAS Institute Inc. 2009).

\section{Results}

Mean $\pm \mathrm{SD} \mathrm{PM}_{2.5}$ bound $\sum_{11} \mathrm{PAHs}$ concentration is $2127 \pm$ $1173 \mathrm{ng} / \mathrm{m}^{3}$, range $319-4282 \mathrm{ng} / \mathrm{m}^{3}$ for wood stoves; and $158 \pm 106 \mathrm{ng} / \mathrm{m}^{3}$, range $38-355 \mathrm{ng} / \mathrm{m}^{3}$ for charcoal stoves. Similarly, Mean \pm SD PM $_{2.5-10}$ bound $\sum_{11}$ PAHs concentration is $73 \pm 43 \mathrm{ng} / \mathrm{m}^{3}$, range $23-144 \mathrm{ng} / \mathrm{m}^{3}$ for wood stoves; and $22 \pm 8 \mathrm{ng} / \mathrm{m}^{3}$, range $8-32 \mathrm{ng} / \mathrm{m}^{3}$ for charcoal stoves. The distribution profile of eleven $\mathrm{PM}_{2.5}$ and $\mathrm{PM}_{2.5-10}$ bound PAHs generated from wood and charcoal stoves is presented in Figures 2(a) and (b), respectively. Concentrations of $\sum_{11} \mathrm{PAHs}$ in kitchens with wood stoves were considerably greater than kitchens with charcoal stoves for $\mathrm{PM}_{2.5}$ bound PAHs $(p=0.0003)$ and $\mathrm{PM}_{2.5-10}$ bound PAHs $(p=0.0024)$. 
The composition of $\mathrm{PM}_{2.5}$ bound PAHs as a percentage of $\sum_{11} \mathrm{PAHs}\left(\mathrm{PM}_{2.5}+\mathrm{PM}_{2.5-10}\right)$ range from $93 \%-98 \%$ (average 96\%) for wood stoves, and from $60 \%-93 \%$ (average 84\%) for charcoal stoves. The abundant $\mathrm{PM}_{2.5}$ bound PAHs in kitchens with wood stoves were PYR, $\mathrm{BaP}$, FLT and DBA constituting $60 \%$ of $\sum_{11} \mathrm{PAHs}$, and DBA, BbF, BaP and PHE representing 63\% for charcoal stoves. Medium molecular weight (MMW) $\mathrm{PM}_{2.5}$ bound PAHs with 4-condensed rings [FLT, PYR, BaA, CHY] were mostly present in kitchens with wood stoves representing 50\% compared with 20\% for charcoal stoves Figure 3. Higher molecular weight (HMW) $\mathrm{PM}_{2.5}$ bound PAHs [BbF, BkF, BaP, DBA, BgP] with 5- and 6-condensed rings constituted $44 \%$ for kitchens with wood stoves compared with $66 \%$ for charcoal stoves Figure 3.

The $\mathrm{BaP}$ equivalent concentrations (a measure to assess PAH carcinogenic potency) for $\mathrm{PM}_{2.5}$ bound PAHs among kitchens with wood stoves range from 128 - 1130 $\mathrm{ng} / \mathrm{m}^{3}$, (average $616 \mathrm{ng} / \mathrm{m}^{3}$ ); and $13-144 \mathrm{ng} / \mathrm{m}^{3}$, (average $58 \mathrm{ng} / \mathrm{m}^{3}$ ) for charcoal stoves Figure 4. The mean

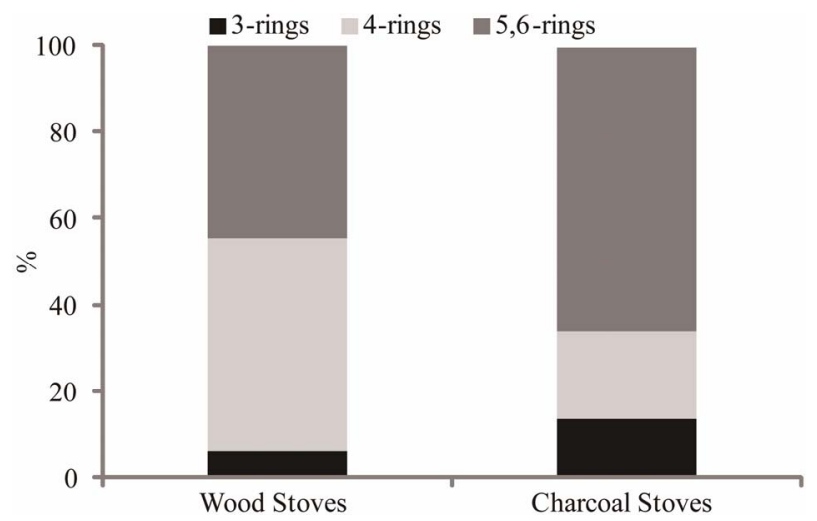

Figure 3. Ring number distribution of $\mathbf{P M}_{2.5}$ bound PAHs in kitchens with wood and charcoal stoves expressed as percentage. 3-rings (PHE \& ANT) represent lower molecular weight PAHs; 4-rings (FLT, PYR, BaA \& CHY) represent medium molecular weight PAHs; and 5,6-rings (BbF, BkF, BaP, DBA \& BgP) represents higher molecular weight PAHs.

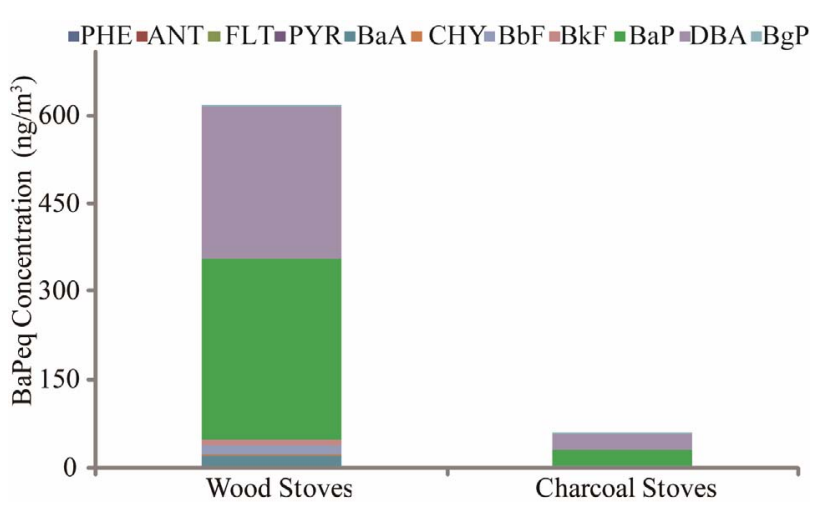

Figure 4. Estimated BaPeq concentrations in kitchens with wood and charcoal stoves for $\mathbf{P M}_{2.5}$ PAHs.
BaPeq concentration was 11 times higher in kitchens with wood stoves relative to charcoal stoves. The contribution of individual PAH to total BaPeq concentration is presented in Figure 4. Mean BaP contributed $50 \%$ and $43 \%$ to total BaPeq for wood and charcoal stoves, respectively. The contribution of the more carcinogenic PAHs "CANPAHs" (BaA, CHY, BbF, BkF, BaP, and DBA) to total BaPeq concentration was more than $99 \%$ for either wood or charcoal stove. These results suggest that carcinogenic $\mathrm{PM}_{2.5}$ bound PAHs played an important role in total BaPeq from health risk view point.

Mean $\mathrm{PM} \pm \mathrm{SD}$ concentration in kitchens with wood and charcoal stoves is presented in Figure 5(a). The range of PM concentration for kitchens with wood stoves was $672-3237 \mu \mathrm{g} / \mathrm{m}^{3}$, and $75-537 \mu \mathrm{g} / \mathrm{m}^{3}$ for charcoal stoves. Mean PM concentration indicated 5.4 times particulate pollution in kitchens with wood stoves compared with charcoal stoves. Mean $\mathrm{CO} \pm \mathrm{SD}$ concentration in kitchens with wood and charcoal stoves is presented in Figure 5(b). The range of $\mathrm{CO}$ concentration for kitchens with wood and charcoal stoves was $16-51 \mathrm{ppm}$ and 14 $95 \mathrm{ppm}$, respectively. The maximum 1-hr time averaged $\mathrm{CO} \pm \mathrm{SD}$ concentration for every kitchen with wood was $44 \pm 21$, and $77 \pm 49$ for charcoal stoves. The WHO recommended guideline for $1-\mathrm{hr} \mathrm{CO}$ exposure (26 ppm) was exceeded in $90 \%$ of the kitchens with wood stoves and

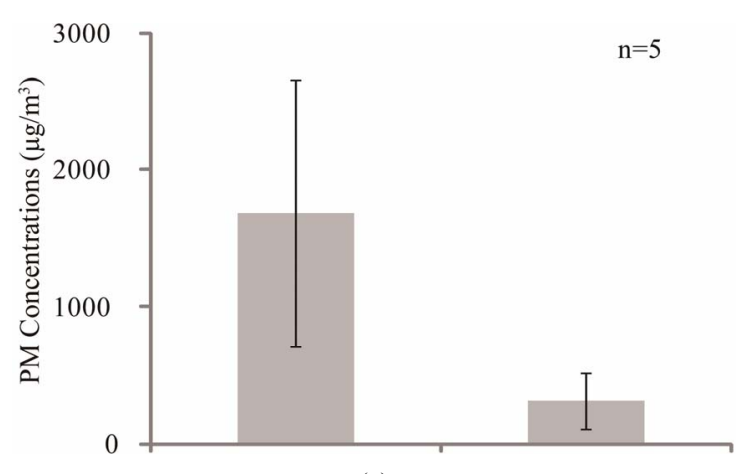

(a)

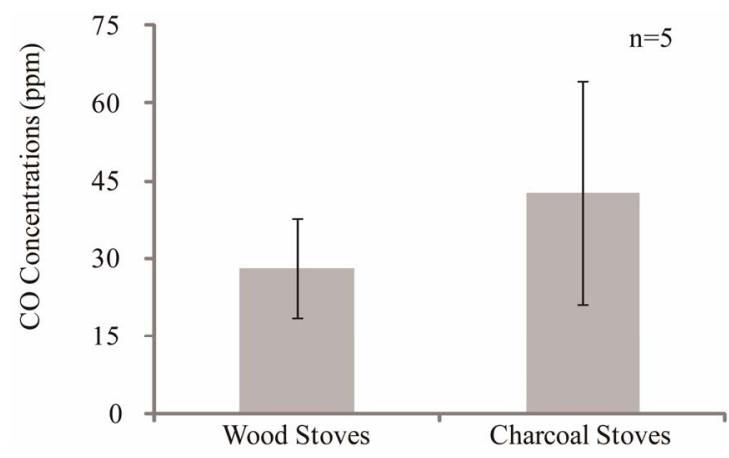

(b)

Figure 5. Mean (box) \pm standard deviation concentrations for (a) PM and (b) CO in kitchens with wood and charcoal stoves. Error bar represent one standard deviation from the mean. 
all of the kitchens with charcoal stoves. There was a significant difference between mean 1 -hr vs. 4-hr CO exposures for kitchens with wood stoves $(p=0.025$; t-test), and $(p=0.032$; t-test) for charcoal stoves. A probable reason for the observed difference could be due to the addition of fuels during cooking activities.

\section{Discussion}

Particulate bound PAHs were significantly higher in kitchens with wood stoves than charcoal stoves. This observation could probably be due to the burning conditions and emission characteristics of the two fuels. Charcoal burns much hotter than wood, hence, it emits little or no smoke, but the reverse is true for wood. PAHs production during biomass burning is a multi-step process that is hinged on progressive aromatization and surface reaction yield [30], and the higher yield of PAHs in kitchens with wood stoves relative to charcoal stoves could suggest that the above mentioned processes are more favored in wood fires. Thus, the pattern of particulate PAHs pollution between wood and charcoal in the current study is consistent with the literature $[19,31,32]$.

The total $\mathrm{PM}_{2.5}$ bound PAHs in the current study was compared with another study using similar PAH members Figure 6(a). From the figure, total concentration of PAHs in the referred study [24] was higher compared with what the current study reported for kitchens with wood stoves. The observed elevation of total PAHs in the aforementioned study could be due to the mixture of wood, leaves, twigs, crop residues used for cooking in rural India, for which emission may vary. We also compared total $\mathrm{PM}_{2.5}$ bound $\mathrm{PAHs}$ with a similar study in Tanzania [19] by using related PAH members from kitchens with wood and charcoal stoves Figures 6(a) and (b). Elevated total $\mathrm{PM}_{2.5}$ bound PAHs was again observed in the referred study relative to this study. The difference in concentrations could perhaps be explained by the cooking practice in Tanzania, as kitchen doors and windows were partly closed during cooking, thereby reducing dispersion of particulate PAHs outdoor through ventilation. The levels of PAHs especially BaP was high in a controlled experiment where ventilation was restricted [33].

The composition of $\sum_{11} \mathrm{PAHs}$ indicated that PAHs were chiefly associated with $\mathrm{PM}_{2.5}$ for both wood and charcoal stoves. Evidently, there is higher amount of PAHs associated with $\mathrm{PM}_{2.5}$ in kitchens with wood stoves than charcoal stoves. In agreement with two previous studies, wood smoke largely contain particles with size less than $2.5 \mu \mathrm{m}[34,35]$. The high content of $\mathrm{PM}_{2.5}$ PAHs would suggest that PAHs released from wood smoke usually coagulate or condense after emission and subsequently collected during measurement. Particle size distribution is important for human exposure and risk

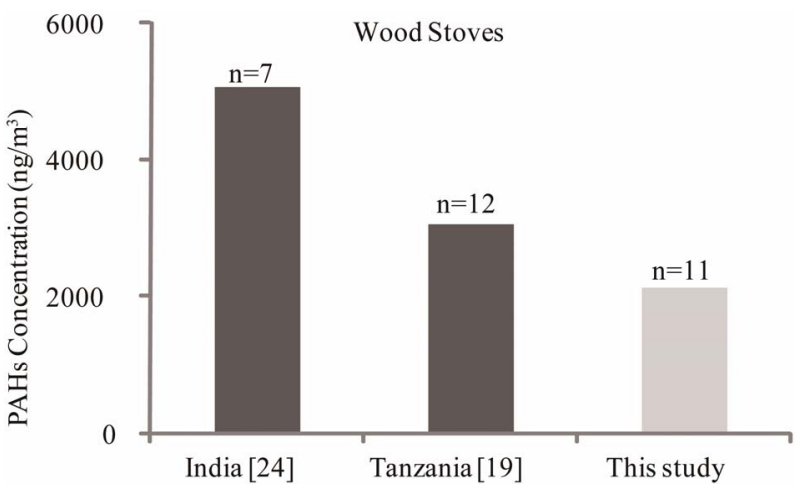

(a)

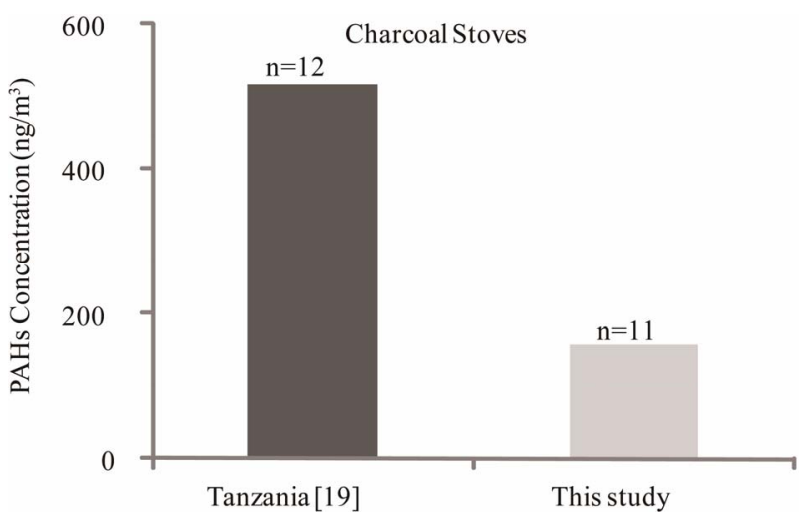

(b)

Figure 6. Comparison of total PAHs with other studies. Total concentrations of $\mathrm{BaA}, \mathrm{CHY}, \mathrm{BbF}, \mathrm{BkF}, \mathrm{BjF} \mathrm{BaP}$, DBA was computed for [24]; and PHE, ANT, FLT, PYR, $\mathrm{BaA}, \mathrm{CHY}, \mathrm{BbF}, \mathrm{BkF}, \mathrm{BjF}$ BaP, DBA and BgP were similarly computed for [19]. $n=$ the number of similar PAH members between the studies; but as for [19], $n=12$ because $\mathrm{BbF}, \mathrm{BkF}$ and $\mathrm{BjF}$ co-eluted; and $\mathbf{n}=7$ for [24] given the fewer number of PAHs measured.

assessment, because toxicological studies have implicated exposure to these particles to various health endpoints, as they are determined to which part of the respiratory tract particles are deposited.

Though MMW PAHs are much more semi volatile in nature, and can occur in both gaseous and particulate phases, their presence generally in the particle phase could be due to slow accumulation and cooling process of plumes of wood smoke. These processes might have accounted for the relative high proportion of $\mathrm{PM}_{2.5}$ bound MMW PAHs in the current study. It has been observed that MMW PAHs are dominant in wood smoke [36,37], and we share similar viewpoint given our results for MMW PAHs. On the contrary, the low proportion of $\mathrm{PM}_{2.5}$ bound MMW PAHs for kitchens with charcoal stove could be attributed to low emission of smoke during charcoal fires, since charcoal burns in a smoldering form (without flames) after it is lit up. Also, charcoal production involves wood pyrolysis through carbonization, and it could represent an important process in the 
loss of the more volatile MMW PAHs. Notably is the dominance of HMW in charcoal smoke, which may suggest that these compounds could persist during the carbonization process.

Diagnostic ratios of PAHs isomers are used to identify the origin of aerosols as part of source apportionment studies. In addition, they can serve as markers or tracers of pollution sources. The ratios of PHE/PHE + ANT, $\mathrm{FLT} / \mathrm{FLT}+\mathrm{PYR}$ and $\mathrm{BaA} / \mathrm{BaA}+\mathrm{CHY}$ obtained from combusting biomass fuels were compared with other studies in the literature Table 1. Generally, the ratios from the same source (fuel type) are consistent with the other studies. There is, however, slight variation in the ratios between the present study and studies in the literature, and we associated this observation to the particulate and gaseous emissions collected, sampling proximity to the source, or the difference in study design etc, between the studies.

Mean $\mathrm{BaP}$ concentration for kitchens with wood and charcoal stoves were $\left(308 \mathrm{ng} / \mathrm{m}^{3}\right)$ and $\left(25 \mathrm{ng} / \mathrm{m}^{3}\right)$, respectively. The mean $\mathrm{BaP}$ concentration for either wood or charcoal stove is well below those reported in occupational environments for coke oven in Norway (37.0 $\mu \mathrm{g} / \mathrm{m}^{3}$ ) during area measurement for particulate PAHs [40]; carbon anode production in Switzerland (1.15 $\mu \mathrm{g} / \mathrm{m}^{3}$ ) during personal measurement for gaseous and particulate PAHs [41]; but higher than in neighborhoods with high traffic density in Canada $\left(22.9 \mathrm{ng} / \mathrm{m}^{3}\right)$ [42]. The reported $\mathrm{BaP}$ concentration for either wood or charcoal is well above the WHO margin of safety $\left(1 \mathrm{ng} / \mathrm{m}^{3}\right)$ in the current study. Even the BaPeq concentration which expresses the carcinogenic potency of PAH mixture is not negligible, and should be taken into account for health protection in the future, particularly the health of women (chief cook) and children, given their frequencies and length of time they may spend in the kitchen.

The pattern of particulate air pollution was higher in kitchens with wood stoves than charcoal stoves, and this would indicate that charcoal stoves emit less particulate matter. This finding is in accordance with existing evidence $[18,20]$. The mean PM concentration $\left(1686 \mu \mathrm{g} / \mathrm{m}^{3}\right)$ for kitchens with wood stoves was higher relative two previous studies conducted in similar indoor environment in Africa. For instance, mean $\mathrm{PM}_{10}$ concentration during cooking in Mozambique was $1200 \mu \mathrm{g} / \mathrm{m}^{3}$ [21], and another study in Tanzania reported mean $\mathrm{PM}_{10}$ concentration of $656 \mu \mathrm{g} / \mathrm{m}^{3}$ during the same task [20]. But, the mean $\mathrm{PM}_{10}$ concentration $5260 \mu \mathrm{g} / \mathrm{m}^{3}$ reported in India [24], was higher relative to the mean level in this study. Factors responsible for the difference in concentrations of indoor air pollutants have been reported to be; the type of biomass burnt, stove type, burning intensity, kitchen area, ventilation rate, spatial distribution of pollutants, duration of monitoring etc, for which these factors may vary in emission rate $[15,43]$.

Particulate matter is the widely studied indicator species of indoor air pollution. The WHO has recommended $50 \mu \mathrm{g} / \mathrm{m}^{3}$ for $24-\mathrm{hr} \mathrm{PM}_{10}$ exposure in ambient air. The monitoring period for PM in this study was limited to 4-hr. Although all the kitchens had mean level that exceeded WHO 24-hr guideline, we would expect the 24-hr mean to be lower than the current reported value, because of the inclusion of non burning periods. Epidemiological studies on large populations have not been able to identify a threshold concentration below which airborne PM has no effect on health [44], but adverse effects have been observed in many studies. Hence, the levels of PM reported in the study are high enough

Table 1. Diagnostic PAHs ratios obtained in this study and other studies in the literature.

\begin{tabular}{|c|c|c|c|c|c|}
\hline PM & Fuel type & $\mathrm{PHE} / \mathrm{PHE}+\mathrm{ANT}$ & FLT/FLT + PYR & $\mathrm{BaA} / \mathrm{BaA}+\mathrm{CHY}$ & Reference \\
\hline $\mathrm{PM}_{2.5}$ & Wood & $0.77 \pm 0.12$ & $0.43 \pm 0.09$ & $0.54 \pm 0.05$ & This study \\
\hline $\mathrm{PM}_{2.5-10}$ & Wood & $0.83 \pm 0.05$ & $0.55 \pm 0.17$ & $0.52 \pm 0.06$ & This study \\
\hline $\mathrm{PM}_{2.5}$ & Charcoal & $0.87 \pm 0.06$ & $0.60 \pm 0.11$ & $0.42 \pm 0.07$ & This study \\
\hline $\mathrm{PM}_{2.5-10}$ & Charcoal & $0.88 \pm 0.05$ & $0.57 \pm 0.05$ & $0.43 \pm 0.10$ & This study \\
\hline $\mathrm{PM}+\mathrm{Gas}$ & Wood & $0.82 \pm 0.01$ & $0.56 \pm 0.05$ & $0.54 \pm 0.08$ & {$[38]$} \\
\hline $\mathrm{PM}+\mathrm{Gas}$ & Charcoal & 0.79 & 0.32 & 0.36 & {$[32]$} \\
\hline $\mathrm{PM}+\mathrm{Gas}$ & Wood & 0.71 & 0.67 & 0.49 & {$[32]$} \\
\hline $\mathrm{PM}+\mathrm{Gas}$ & Wood & & 0.56 & & [39] \\
\hline $\mathrm{PM}_{2.5}$ & Wood & 0.82 & 0.51 & 0.52 & [19] \\
\hline $\mathrm{PM}_{2.5}$ & Charcoal & 0.94 & 0.44 & 0.47 & [19] \\
\hline
\end{tabular}


to produce negative health effects such as acute respiratory infections in children and asthma and chronic obstructive pulmonary diseases in susceptible adult population.

Generally, mean CO levels in kitchens with charcoal stoves are elevated relative to wood stoves. We share similar observation with a previous study [16], and this finding could further support existing evidence that charcoal emits more CO than wood. Mean CO in kitchens with wood stove $(28 \mathrm{ppm})$ was high compared with the levels measured during cooking period (14 ppm) in Tanzania [20], but low compared with the levels (118 ppm) measured during standard cooking tests in Guatemala [45]. Maximum 1-hr arithmetic mean exposure for kitchens with wood stoves was low relative to a previous study in Pakistan [46]. The difference in concentrations could be explained by the same factors previously mentioned in the above section for PM. Given the potentially fatal nature of acute $\mathrm{CO}$ incidents, short term exposure (maximum 1-hr) mean value would carry critical information especially for cardiovascular patients. $\mathrm{CO}$ is a toxic non irritating gas with high affinity for oxygen, and it reduces oxygen carrying capacity to vital organs in the body. Thus, cooks described here are exposed to hazardous levels of CO during cooking. Traditionally, women carry young children to the kitchens, and they are another victim of continuous and direct contact with such high levels of exposure. The impact of $\mathrm{CO}$ exposure in children would potentially be severe given the immature state of their anatomy [47]. Therefore they should be advised on the potential health risks associated with such high levels of exposure to reduce impact.

The levels of indoor air toxics measured in this study are high compared with the levels reported for cleaner fuels elsewhere $[19,46,48]$. This intuitively would suggest that a progression to cleaner fuels would be a better alternative to reduce the risks associated with exposure to biomass smoke in rural Sierra Leone. With the persistent increase of the cost of cleaner energy, this may be difficult to achieve in the short term. In the interim, an improvement in ventilation system, by a way of installing a long chimney on charcoal stove could be a measure to encourage the use of charcoal instead of wood stove, since relatively lower emissions of PAHs and PM were derived from charcoal stoves. Given the lack of information on indoor air toxics in Sierra Leone, it is anticipated that these results would provide baseline information for subsequent intervention programmes aim at reducing the high exposure levels to biomass smoke.

Given the fact that several inhalable toxic chemicals are released during biomass burning, indoor air pollution could be considered to constitute a major environmental health concern that needs attention in Sierra Leone. Data to quantitatively support disease burden from this envi- ronmental risk factor is lacking, but the levels of exposure to particulate PAHs, PM and CO reported is high relative to health guidelines, and this would provide further insight into the magnitude of indoor air pollution in rural areas of developing countries where many people rely on biomass fuels. The problem may be exacerbated with the intrusion of toxic air pollutants from outdoors and from other existing indoor sources such as environmental tobacco smoke.

In summary, concentrations of indoor toxic air pollutants (PAHs, PM and $\mathrm{CO}$ ) were measured during cooking in kitchens with traditional biomass stoves in rural Sierra Leone. Wood stoves produced greater contents of PAHs and PM while charcoal stoves generated more CO. PAHs were largely associated with $\mathrm{PM}_{2.5}$ than $\mathrm{PM}_{2.5-10}$. The results for PAHs, $\mathrm{PM}$ and $\mathrm{CO}$ were high compared with the WHO recommended guidelines which raise the concern with regards to environmental health risks. These findings generally have implications for women's health in rural communities in Sierra Leone, given their frequent visit in the kitchen. We believe that there would be an improvement in air quality, a prerequisite to improve health, should cleaner fuels be adopted in these communities, given the existing evidence of low emissions of PAHs, PM and CO from cleaner fuels.

\section{Acknowledgements}

This study was supported by Yokohama National University, International Environmental Leaders Program in Sustainable Living with Environmental Risks funded by Strategic Funds for the Promotion of Science and Technology, Japan and Global Center of Excellence (Global COE) Program, "Global Eco-Risk Management from Asian Viewpoints" Yokohama National University.

The authors thank staff members and students of Njala University, Sierra Leone, especially Dr. Bashiru M. Koroma for their invaluable support they provided during the monitoring period. We are also grateful to all the residents of the investigated homes in the two communities for their warmth.

\section{REFERENCES}

[1] WHO, "Indoor Air Pollution Takes Heavy Toll on Health," 2007.

http://www.who.int/mediacentre/news/notes/2007/np20/e n/index.html

[2] WHO, "Fuel for Life: Household Energy and Health," 2006.

http://www.who.int/indoorair/publications/fuelforlife.pdf

[3] N. Bruce, R. Perez-Padilla and R. Albalak, "Indoor Air Pollution in Developing Countries: A Major Environmental and Public Health Challenge," Bulletin of the World Health Organization, Vol. 78, No. 9, 2000, pp. 1078-1092. 
[4] IARC, "Monographs on the Evaluations of Carcinogenic Risks to Humans, Volume 92. Some Non Heterocyclic Polycyclic Aromatic Hydrocarbons and Some Related Exposures, IARC, Lyon, 2010," 2010. http://monographs.iarc.fr/Eng/Monographs/vol92/mono92.pdf

[5] T. T. Hien, P. P. Nam, Y. Sadanaga, T. Kameda, N. Takenaka and H. Bandow, "Comparison of Particle-Phase Polycyclic Aromatic Hydrocarbons and Their Variability Causes in the Ambient Air in Ho Chi Minh City, Vietnam and in Osaka, Japan, during 2005-2006," Science of the Total Environment, Vol. 382, No. 1, 2007, pp. 70-81. doi:10.1016/j.scitotenv.2007.04.013

[6] S. Kong, X. Ding, Z. Bai, B. Han, L. Chen, J. Shi and Z. Li, "A Seasonal Study of Polycyclic Aromatic Hydrocarbons in PM2.5 and $\mathrm{PM}_{2.5-10}$ in Five Typical Cities of Liaoning Province, China," Journal of Hazardous Materials, Vol. 183, No. 1-3, 2010, pp. 70-80. doi:10.1016/j.jhazmat.2010.06.107

[7] J. L. Mumford, R. S. Chapman, D. B. Harris, X. Z. He, S. R. Cao, Y. L. Xian and Z. M. Li, "Indoor Air Exposure to Coal and Wood Combustion Emissions Associated with High Lung Cancer Rate in Xuan Wei, China," Environment International, Vol. 15, No. 1-6, 1989, pp. 315-320.

[8] C. Boman, A. B. Forsberg and B. G. Jarvholm, "Adverse Health Effects from Ambient Air Pollution in Relation to Residential Wood Combustion in Modern Society," Scandenavian Journal of Work, Environment and Health, Vol. 29, No. 4, 2003, pp. 251-260. doi:10.5271/sjweh.729

[9] L. P. Naeher, M. Brauer, M. Lipsett, J. T. Zelikoff, C. D. Simpson, J. Q. Keoeing and K. R. Smith, "Woodsmoke Health Effects: A Review," Inhalation Toxicology, Vol. 19, No. 1, 2007, pp. 67-106. doi:10.1080/08958370600985875

[10] B. C. Boman, A. B. Forsberg and T. Sandstrom, "Shedding New Light on Wood Smoke: A Risk Factor for Respiratory Health," European Respiratory Journal, Vol. 27, No. 3, 2006, pp. 446-447. doi:10.1183/09031936.06.00000806

[11] M. Ezzati and D. M. Kammen, "Indoor Air Pollution from Biomass Combustion and Acute Respiratory Infections in Kenya: An Exposure-Response Study," The Lancet, Vol. 358, No. 9282, 2001, pp. 619-624. doi:10.1016/S0140-6736(01)05777-4

[12] L. E. Bautista, A. Correa, J. Baumgartner, P. Breysse and G. M. Matanoski, "Indoor Charcoal Smoke and Acute Respiratory Infections in Young Children in the Dominican Republic," American Journal of Epidemiology, Vol. 169, No. 5, 2009, pp. 572-580. doi:10.1093/aje/kwn372

[13] J. Regalado, R. Perez-Padilla, R. Sansores, J. I. P. Ramirez, M. Brauer, P. Pare and S. Vedal, "The Effect of Biomass Burning on Respiratory Symptoms and Lung Function in Rural Mexican Women," American Journal of Respiratroy and Critical Care Medicine, Vol. 174, No. 8, 2006, pp. 901-905.

[14] J. R. Goldsmith, "Carbon Monoxide and Coronary Disease: A Review," Environmental Research, Vol. 10, No. 2, 1975, pp. 236-248. doi:10.1016/0013-9351(75)90087-0

[15] K. R. Smith, S. Mehta and M. Maeusezahl-Feuz, "Indoor Air Pollution from Household Solid Fuels Use," In: M.
Ezzati, A. D. Lopez, A. Rodgers and C. J. L. Murray, Eds., Comparative Quantification of Health Risks: Global and Regional Burden of Disease Attributable to Selected Major Risk Factors, World Health Organization, Geneva, 2004, pp. 1435-1493.

[16] D. G. Fullerton, S. Semple, F. Kalambo, S. Suseno, R. Malamba, G. Henderson, J. G. Ayres and S. B. Gordon, "Biomass Fuel Use and Indoor Air Pollution in Homes in Malawi," Occupational and Environmental Medicine, Vol. 66, No. 11, 2009, pp. 777-783. doi:10.1136/oem.2008.045013

[17] C. Viau, G. Hakizimana and M. Bouchard, "Indoor Exposure to Polycyclic Aromatic Hydrocarbons and Carbon Monoxide in Traditional Houses in Burundi," International Archive of Occupational Environmental Health, Vol. 73, No. 5, 2000, pp. 331-338. doi:10.1007/s004209900112

[18] M. Ezzati, M. B. Mbinda and M. D. Kammen, "Comparison of Emissions and Residential Exposure from Traditional and Improved Cookstoves in Kenya," Environmental Science and Technology, Vol. 34, No. 4, 2000, pp. 578-583. doi:10.1021/es9905795

[19] M. E. Titcombe and M. Simcik, "Personal and Indoor Exposure to PM2.5 and Polycyclic Aromatic Hydrocarbons in the Southern Highlands of Tanzania: A PilotScale Study," Environmental Monitoring and Assessment, Vol. 180, No. 1-4, 2010, pp. 461-476. doi:10.1007/s10661-010-1799-3

[20] J. H. Kilabuko, H. Matsuki and S. Nakai, "Air Quality and Acute Respiratory Illness in Biomass Fuel Using Homes in Bagamoyo, Tanzania," International Journal of Environmental Research and Public Health, Vol. 4, No. 1, 2007, pp. 39-44. doi:10.3390/ijerph2007010007

[21] A. Ellegard, "Cooking Fuel Smoke and Respiratory Symptoms among Women in Low Income Areas in Maputo," Environmental Health Perspectives, Vol. 104, No. 9, 1996, pp. 980-985. doi:10.1289/ehp.96104980

[22] J. S. M. Boleij, P. Ruigewaard, F. Heok, H. Thairu, E. Wafula, F. Onyango and H. de-Koning, "Domestic Air Pollution from Biomass Burning in Kenya," Atmospheric Environment, Vol. 23, No. 8, 1989, pp. 1677-1681. doi:10.1016/0004-6981(89)90052-8

[23] E. T. Taylor and S. Nakai, "Prevalence of Acute Respiratory Infections in Women and Children in Western Sierra Leone Due to Smoke from Wood and Charcoal Stoves," International Journal of Environmental Research and Public Health, Vol. 9, No. 6, 2012, pp. 2252-2265. doi:10.3390/ijerph9062252

[24] F. A. Ansari, A. H. Khan, D. K. Patel, H. Siddiqui, S. Sharma, M. Ashquin and I. Ahmad, "Indoor Exposure to Respirable Particulate Matter and Particulate-Phase PAHs in Rural Homes in North India," Environmental Monitoring and Assessment, Vol. 170, No. 1-4, 2010, pp. 491497. doi:10.1007/s10661-009-1249-2

[25] R. Jiang and M. L. Bell, "A Comparison of Particulate Matter from Biomass Burning Rural and Non Biomass Burning Urban Households in Northeastern China," Environmental Health Perspective, Vol. 116, No. 7, 2008, pp. 907-914. doi:10.1289/ehp.10622

[26] E. T. Taylor and S. Nakai, "Monitoring the Levels of 
Toxic Air Pollutants in the Ambient Air of Freetown, Sierra Leone," African Journal of Environmental Science and Technology, Vol. 6, No. 7, 2012, pp. 283-292.

[27] K. Hayakawa, N. Terai, P. G. Dinning, K. Akutsu, Y. Iwamoto, R. Etoh and T. Murahashi, "An Online Reduction HPLC/Chemiluinescence Detection for Nitropolycyclic Aromatic Hydrocarbons and Metabolites," Biomedical Chromatography, Vol. 10, No. 6, 1996, pp. 346-350. doi:10.1002/(SICI)1099-0801(199611)10:6<346::AID-B MC605>3.0.CO;2-Y

[28] A. Bhargava, R. N. Khanna, S. K. Bhargava and S. Kumar, "Exposure Risk to Carcinogenic PAHs in Indoor-Air during Biomass Combustion Whilst Cooking in rural India," Atmospheric Environment, Vol. 38, No. 28, 2004, pp. 4761-4767. doi:10.1016/j.atmosenv.2004.05.012

[29] N. R. Khalili, P. A. Scheff and T. M. Holsen, "PAH Source Fingerprints for Coke Ovens, Diesel and Gasoline Engines, Highway Tunnels, and Wood Combustion Emissions," Atmospheric Environment, Vol. 29, No. 4, 1995, pp. 533-542. doi:10.1016/1352-2310(94)00275-P

[30] A. Violi, A. D'Anna and A. D'Alessio, "Modeling of Particulate Formation in Combustion and Pyrolysis," Chemical Engineering Science, Vol. 54, No. 15-16, 1999, pp. 3433-3442. doi:10.1016/S0009-2509(98)00460-6

[31] J. B. Kandpal, R. C. Maheshwari and T. C. Kandpal, "Indoor Air Pollution from Combustion of Wood and Dung Cake and Their Processed Fuels in Domestic Cookstoves," Energy Conservation and Management, Vol. 36, No. 11, 1995, pp. 1073-1079. doi:10.1016/0196-8904(94)00086-F

[32] N. T. K. Oanh, L. B. Reutergardh and N. T. Dung, "Emission of Polycyclic Aromatic Hydrocarbons and Particulate Matter from Domestic Combustion of Selected Fuels," Environmental Science and Technology, Vol. 33, No. 16, 1999, pp. 2703-2709. doi:10.1021/es980853f

[33] S. Gupta, S. Saksena, V. R. Shankar and V. Joshi, "Emission factors and Thermal Efficiencies of Cooking Biofuels from Five Countries," Biomass and Bioenergy, Vol. 14, No. 5-6, 1998, pp. 547-559. doi:10.1016/S0961-9534(98)00010-5

[34] M. D. Hays, C. D. Geron, K. J. Linna and N. D. Smith, "Speciation of Gas-Phase and Fine Particle Emissions from Burning of Foliar Fuels," Environmental Science and Technology, Vol. 36, No. 11, 2002, pp. 2281-2295. doi:10.1021/es0111683

[35] M. J. Kleeman, J. J. Schauer and G. R. Cass, "Size and Composition Distribution of Fine Particulate Matter Emitted from Wood Burning, Meat Charbroiling, and Cigarettes," Environmental Science and Technology, Vol. 33, No. 20, 1999, pp. 3516-3523. doi:10.1021/es981277q

[36] C. Venkataraman, G. Negi, S. B. Sardar and R. Rastogi, "Size Distributions of Polycyclic Aromatic Hydrocarbons in Aerosol Emissions from Biofuel Combustion," Journal of Aerosol Science, Vol. 33, No. 3, 2002, pp. 503-518. doi:10.1016/S0021-8502(01)00185-9

[37] E. Hedberg, A. Kristensson, M. Ohlsson, C. Johansson, P. A. Johansson, E. Swietlicki, V. Vesely, U. Wideqvist and R. Westerholm, "Chemical and Physical Characterization of Emissions from Birch Wood Combustion in a Wood Stove," Atmospheric Environment, Vol. 36, No. 30, 2002, pp. 4823-4837. doi:10.1016/S1352-2310(02)00417-X

[38] J. M. Barbosa, N. Re-Poppi and M. Santiago-Silva, "Polycyclic Aromatic Hydrocarbons from Wood Pyrolysis in Charcoal Production Furnaces," Environmental Research, Vol. 101, No. 3, 2006, pp. 304-311. doi:10.1016/j.envres.2006.01.005

[39] J. J. Schauer, M. J. Kleeman, G. R. Cass and B. R. T. Simoneit, "Measurement of Emissions from Air Pollution Sources. 3 C1-C29 Organic Compounds from Fireplace Combustion of Wood," Environmental Science and Technology, Vol. 35, No. 9, 2001, pp. 1716-1728. doi:10.1021/es001331e

[40] A. Bjorseth, O. Bjorseth and P. E. Fjeldstad, "Polycyclic Aromatic Hydrocarbons in the Work Atmospher. II. Determination in a Coke Plant," Scandenavian Journal of Work, Environment and Health, Vol. 4, No. 3, 1978, pp. 224-236. doi:10.5271/sjweh.2703

[41] T. Petry, P. Schmid and C. Schlatter, "The Use of Toxic Equivalency Factors in Assessing Occupational and Environmental Health Risks Associated with Exposure to Airborne Mixtures of Polycyclic Aromatic Hydrocarbons," Chemosphere, Vol. 32, No. 4, 1996, pp. 639-648. doi:10.1016/0045-6535(95)00348-7

[42] A. Vyskocil, Z. Fiala, V. Chenier, L. Krajak, E. Ettlerova, J. Bukac, C. Viau and S. Emminger, "Assessment of Multipathway Exposure of Small Children to PAHs," Environmental Toxicology and Pharmacology, Vol. 8, No. 2, 2000, pp. 111-118. doi:10.1016/S1382-6689(00)00032-6

[43] K. Balakrishnan, S. Sankar, J. Parikh, R. Padmavathi, K. Srividya, V. Venugopal, P. Swarma and L. P. Vijay, "Daily Average Exposures to Respirable Particulate Matter from Combustion of Biomass Fuels in Rural Households of Southern India," Environmental Health Perspectives, Vol. 110, No. 11, 2002, pp. 1069-1075. doi:10.1289/ehp.021101069

[44] WHO, "Health Aspects of Air Pollution with Particulate Matter, Ozone and Nitrogen Dioxide: Report on a WHO Working Group, Bonn, Germany," 2003.

http://www.euro.who.int/_data/assets/pdf_file/0005/1121 99/E79097.pdf

[45] J. P. McCracken and K. R. Smith, "Emission and Efficiency of Improved Woodburning Cookstoves in Highland Guatemala," Environment International, Vol. 24, No. 7, 1998, pp. 739-747. doi:10.1016/S0160-4120(98)00062-2

[46] A. R. Siddiqui, K. Lee, D. Bennett, X. Yang, K. H. Brown, Z. A. Bhutta and E. B. Gold, "Indoor Carbon Monoxide and PM2.5 Concentrations by Cooking Fuels in Pakistan," Indoor Air, Vol. 19, No. 1, 2009, pp. 75-82. doi:10.1111/j.1600-0668.2008.00563.x

[47] K. R. Smith, J. M. Samet, I. Romieu and N. Bruce, "Indoor Air Pollution in Developing Countries and Acute Respiratory Infections in Children," Thorax, Vol. 55, No. 6, 2000, pp. 518-532. doi:10.1136/thorax.55.6.518

[48] S. Liu, Y. Zhou, X. Wang, D. Wang, J. Lu, J. Zheng, N. Zhong and P. Ran, "Biomass Fuels Are the Probable Risk Factor for Chronic Obstructive Pulmonary Disease in Rural South China," Thorax, Vol. 62, No. 10, 2007, pp. 889-897. doi:10.1136/thx.2006.061457 


\section{Supplementary Figures}

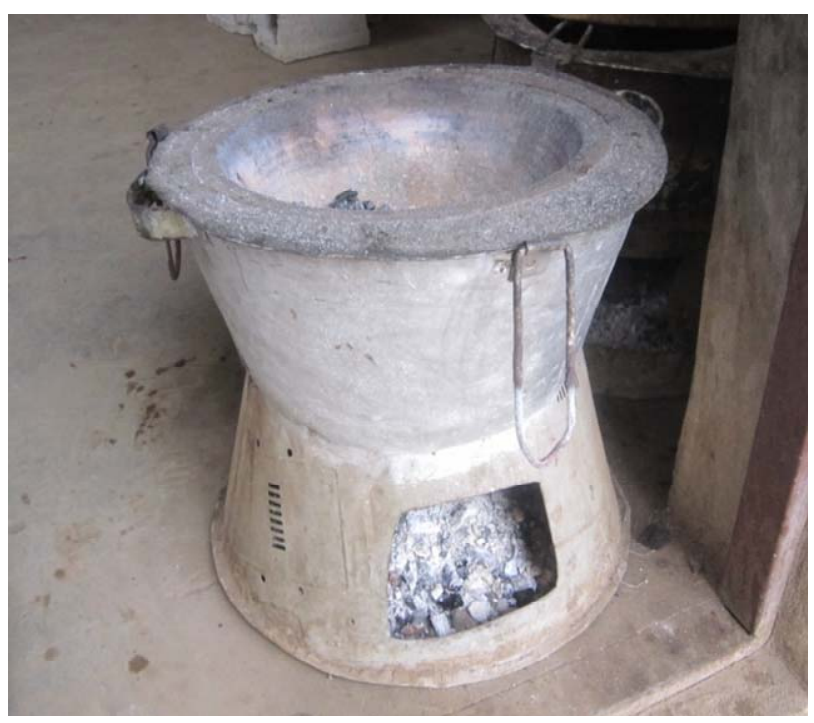

Figure 1. Charcoal stove.

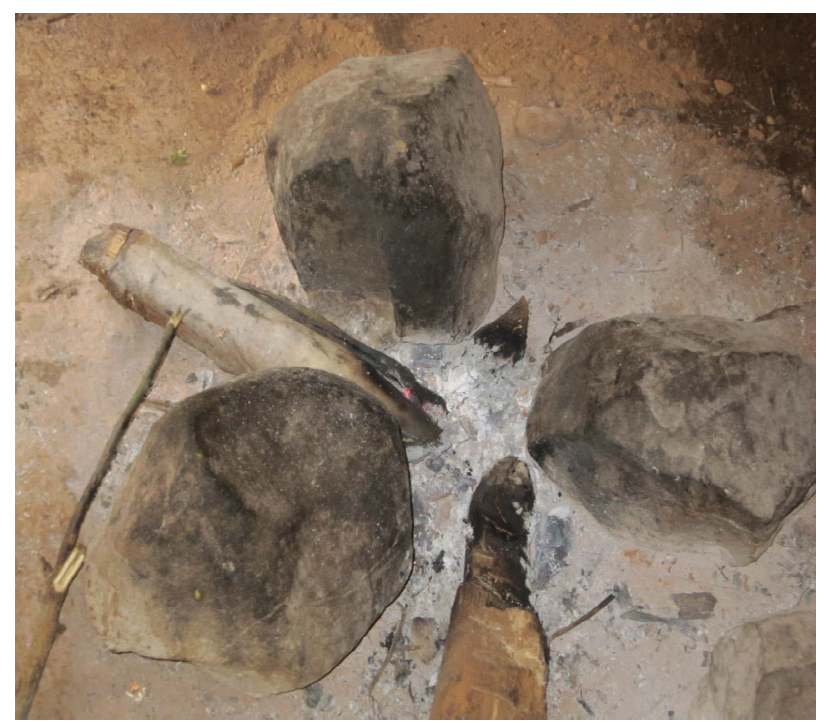

Figure 2. Wood stove. 